\title{
FORECASTING INFORMATION AND TELECOMMUNICATIONS TECHNOLOGIES IN AN ERA OF CHANGE: WHAT ARE THE IMPLICATIONS FOR PERSONAL TRAVEL?
}

\author{
Metin ŞENBİL
}

Received: 12.06.2009; Final Text: 03.09.2009

Keywords: information and communication technologies; telephone; activity based travel demand; personal travel; social network.

1. Parts of this study are based on my unpublished Ph.D. Dissertation "The Relationships Between Telecommunications and the Activity System of Individuals" at Kyoto University, Japan. I sincerely acknowledge the support of my supervisor Prof. Ryuichi Kitamura who passed away in February, 2009. I would like to thank the anonymous referees for their suggestions and my colleague Nihan Özdemir Sönmez who read the manuscript
Information and communication technologies (ICT) are enjoying fast development which immediately translate into their market enhancements nowadays (1). ICT relaxes both space and time constraints while allowing instant information exchange. In terms of activity-based travel demand, ICT use might substitute, complement or modify individual activity-travel behavior at varying degrees. On the other hand, ICT network externalities complement the social network in positive directions. Overall, ICT use complements activity-travel demand by increasing the number of activity engagements. Besides, similar to the conventional telephone, ICT has been transforming the modern society and life in many ways as well.

\section{INTRODUCTION}

Information and communications technologies (hereafter ICT) have been improving both in diversity and reliability par excellence. More than anything, this process is fast proceeding to a seamless communications environment. That is to say, as far as circumstances allow, one can communicate wherever and whenever wishes to, hence relaxing constraints imposed by the ambient environment, biology as well as institutions.

Therefore, there are vast implications for both production and reproduction of space and the selves. In this respect, without much doubt one can purport to say that ICT has an important role in maintaining and sustaining modern life. However, their implications in this era of change from industrial society to post-industrial, informational society still remains to be explored both theoretically and emprically.

The advent of telephone and its gradual adoption by the society is a valuable example in this context. Along with other technological breakthroughs, telephone has enabled both vertical and horizontal urban expansion. Besides, telephone has enabled millions of interacting parties to coordinate their mutual information and actions. Today, it has ascended to become one of the basic ingredients of the human civilization. 
Acccordingly, during its journey in history, the telephone has also attracted many studies. For example, the name of this study is inspired from one of them: de Sola Pool's impact study named as "Forecasting the Telephone" (de Sola Pool, 1983) which is a retrospective study revealing on the forecasts (amount to 186 forecasts in total) made about the effects of the telephone on the society. As similar to all other forecasts made on technology, some turned out to be true, while others not. To our interest in this study is a classification developed by de Sola Pool to categorize these forecasts:

Type A: Telephone will be used in manner $x$.

Type B: Telephone will be used in manner $x$, so society will be changed in manner $y$.

Type C: With the wide use of phones, society will be changed in manner $y$.

Type D: Other propositions about the impacts.

With these types of generic impacts, de Sola Pool (1983) gives a collection of technology assessments that writers of journals, magazines and newspapers have made since the advent of the conventional telephone in 1876 up to 1940. Those related to individual activities such as work, shopping, recreation, etc. (note that the term individual activity will be used interchangeably with activity in the text) directly and, in most of the instances, indirectly are indexed under Type A impacts; some of relevant Type A forecasts can be given as follows:

1. Telephone will foster management from distance (de Sola Pool, 1983, 59).

2. Telephone will be used for shopping (de Sola Pool, 1983, 66).

3. Telephone will reduce travels of salesmen (de Sola Pool, 1983, 67).

4. Telephone will speed reporting (de Sola Pool, 1983, 83).

5. The availability of telephone reduces the need to travel (de Sola Pool, 1983, 105).

6. Telephone allows two-way communications in real time terms (de Sola Pool, 1983, 107).

All of the above forecasts are now regarded as fixtures of daily life without much scrutiny and yet disregarded in many respects. Katz (2001) draws attention to this point and notes the plight of telephone (or telecommunications) as "too easily forgotten by lay people and scholars alike is the miracle of being able at any time to place a call to any other subscriber worldwide" (Katz, 2001, 15228). A call can be regarded as the sole basic action of inquiring information about individual activities, the basic ingredient of urban transportation demand.

On the other hand, state or private monopolies in telecommunications are gradually coming to an end by deregulation in the world and are being replaced by free competition. Accordingly, the market has flourished with different commodities and added services including roaming services and switching facilities. So far, deregulation has produced wide range of benefits such as decreasing prices and technological boom in the market. The capacity of the system has been increasing and the different kinds of products have proliferated in the market with increasing paces. The most striking advances have been taken in the wireless communications. 
Mobile phone has proved to be a successful business and an asset for both suppliers and consumers. The reason why mobile phone has become such a celebrated market success might be found in its ability to bring together diverse technologies in itself. The future has been evolving towards the convergence of Palm devices (simple portable computers) and the mobile phones as well as $3 \mathrm{G}^{+}$technologies.

The aim of this study is to reveal the implications of ICT on urban transportation demand from the viewpoint of individual activities. Basic conjecture in this study is that the relationships between ICT use and individual activities are strong enough to change the way individuals live and commence their activities. In this regard, this study refers to trip generation phenomenon from activity-based perspective. It can be said that in many respects, both individual activities and individual trip making behavior are affected by ICT use at varying degrees. Mainly, in the short and middle run, they are substituted, modified, complemented or not affected by telecommunications utilization, and it is likely that many effects will occur simultaneously. In the long (or medium) run, it shall be expected that these effects along with evolving spatial technologies would lead to locational preferences to change and result in locational relocation of both individuals and businesses ceteris paribus.

Although the generic relationships between telecommunications and transportation have been well defined by researchers (Salomon, 1985; 1986; Mokhatarian, 1990), the main source of trips in urban areas, i.e., activities generally are disregarded in many of the analyses. This is partly because of some of the urgent policy considerations that stemmed from the oil shocks of 1970s and directed toward decreasing trip makings of the masses, mainly work commutes made by private car. This has been well reflected in the researches on telecommuting or teleworking. Out of this phenomenon, other tele+ services or policies came into consideration too. Finding statistical evidence of wide tele+ services adoption has stirred academic circles lately. The main emphasis was on alleviating or decreasing or even modifying trip making patterns in certain ways to decrease the side effects of transportation system, e.g., energy consumption, environmental degradation etc. But daily life mainly assumes a different path apart from this simple understanding of tele+ phenomena. Most of the logistics adopted by individuals in order to be organized, or to be synchronized with others require ICT use. Consequently, ICT use help individuals organize their activities in space and time which govern activity durations, schedules, trip chains, trip modes as well as route selection.

The rest of this study is organized as follows. The second section gives a framework about the relationships between ICT and activity-travel behavior without much delving into detailing what ICT or individual activities are. The main focus in this section is to delineate the possible space of interactions between ICT and individual activities. The following section presents a case about two of the widely used telecommunications devices: the fixed telephone and the mobile phone. The section four carries the discussion to the social group level, i.e., the social network. The network externality and the social network are two overlapping features of modern life, which fosters intensive communications. Based on the previous sections, the last section presents further discussion on future prospects of ICT use. 


\section{COMMUNICATIONS AD INFINITUM AND INDIVIDUAL ACTIVITIES IN SILICO}

ICT supplies two-way communications in most of the instances. Besides, added services over simple voice communications or the World Wide Web as well as its smaller constituents facilitate one-way communications too. An individual's main gain from communications is gaining information, which might be utilized in ways that can affect activities in time and space, hence travel demand. Considering activities, the information obtained via ICT is crucial such that it might affect an activity (for example cancelling an activity) which might consequently cause spillover effects on other activities and the organization of activities within different time spans (day, week, month or else) as well.

An activity has specific points in time and space; moreover it has a place in a sequence of activities in a day, week, or month. With respect to the constraints imposed by space and time, activities pursued are products of a decision process known as activity scheduling. Decisions related to activity schedules generally base on individual discretion or collective decisions (for example interrelationships between household members) or authority constraints. Organization of activities in space and time which might be regarded as the kernel for travel demand is assumed to maximize utility or satisfy the individual (or group, e.g., household) wants / needs and desires (or simply utilities).

Hägerstrand (1970) treat activities under combined space and time geographies, where activities emerge as a result of interactions between individuals and the outer world within constraints set by time, space and basic human properties. The outer world comprises many different sorts of interactions in the middle of which individuals stand. Within the possibilities set forward, activities emerge as a part of a schedule special to the individual and are subject to three different constraints which are capability, coupling, authority constraints (Hägerstrand, 1970). Capability constraints "are those which limit the activities of the individual because of his biological construction and/or the tools he can command" (Hägerstrand, 1970, 12). Coupling constraints apply to such questions "where, when and how long the individual must join other individuals, tools and materials in order to produce, consume and transact" (Hägerstrand, 1970,14). Authority constraints apply to the availability of activities within certain time intervals. For example opening and closing of shopping malls determine availability of shopping within a certain time intervals. Authority constraints are implied by the existence of a device called control area or domain. The context of domain refers to "a timespace entity within which things and events are under control of a given individual or a given groups"' (Hägerstrand, 1970, 16).

The usual line of research dealing with ICT effects on trip making has conceptualized four generic effects that are substitution, complementation, modification and neutrality (see Salomon 1985, 1986 and Mokhtarian 1990). Note that the emphasis here is on trips. However, individuals take trips to participate activities at a location; in other words, the demand for activities naturally derives the demand for trips. Therefore these effects have far reaching results as the activities affected are related to other activities in time and space affecting the whole activity-travel agenda in various ways. Considering this, Şenbil and Kitamura (2003) referred to telecommunicating which is an activity for organizing other activities. In addition to its benefit by enabling interaction of spatially apart individuals, 


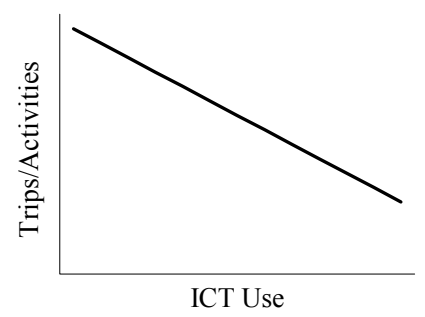

a. Substitution

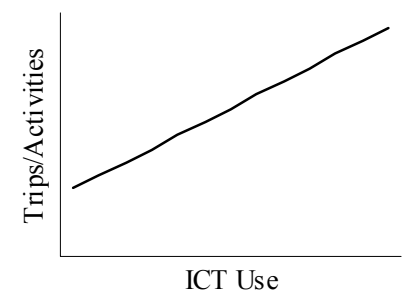

b. Complementation

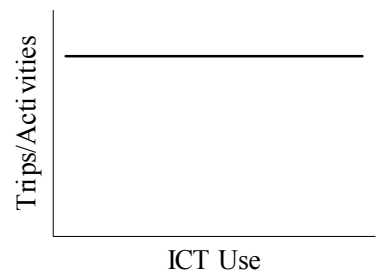

c. Modification or Neutrality
Figure 1. ICT effects on activity and travel behaviour. telecommunications is an activity, which consumes only time but not space. Şenbil and Kitamura (2003) refer to this activity as telecommunicating. So far, with the inclusion of activities, the generic effects can be given as follows (Figure 1):

1. Substitution: As ICT use increases, the number of trips or activity durations decrease, hence they are substituted.

2. Complementation: As ICT use increase, the number of trips and activity durations also increase.

3. Modification: ICT use leads to modification of aspects of trips and/ or activities, such as the route and timing of trips, and the timing, location and sequence of activities.

4. Neutrality: ICT use leads to modification of aspects of trips and/ or activities, such as the route and timing of trips, and the timing, location and sequence of activities

Accordingly, substitution, complementation, modification, and neutrality which are originally developed for trips include individual activities and activity (re)scheduling too. The two modes of activity engagement are physical coupling (such as face-to-face contacts) and virtual coupling (such as ICT contacts) -we ignore other modes of communications such as freight and postal services in this context. The reason behind this is freight and postal services bear lags in translating themselves into activities, but ICT (i.e., telecommunications) is different in character and the effects of telecommunications in spatial and temporal behaviors can be seen immediately in most of the cases. Decision to pursue any activity either by face-to-face or telecommunications is made by the respective properties of the activities.

Telecommunications substitution for activities works in the cases when the use of telecommunications cancels out an activity, shortens activity durations or renders the need to travel to couple with machines and people as redundant (in other words, bringing the activity to the place of existence as in the case of tele+ phenomenon, such as teleworking, teleshopping, telemedicine etc.). Activity substitution by ICT use has attracted relatively less attention from researchers. Direct consequence of canceling out the necessary trip for the obsolete activity might result in assigning released time to other activities either in-home or out-home. Moreover, an unexpected situation may prompt ICT use to inform others about the changed conditions. On the other hand, shortening activity duration might have different results. For example, Reid (1977) reported that in the case of business contacts, contacts made by telecommunications significantly reduce the activity durations (2-10 minutes on the average) while activity 
durations for face-to-face contacts remain within the range of 30-60 minutes on the average. Because of this activity shortening, most businesses resort to more frequent use of telecommunications in order to increase their efficiency. Shortened activity durations might have different implications for different activities on the other hand.

For work and work related activities, shortened activity durations might not indicate direct effects on other activities such as discretionary activities, but it might indicate indirect effects when face-to-face contacts (in the case of less ICT use) might cause physical exhaustion that lead to in-home activities. The reverse is also valid in this case, telecommunicating would release time for out-home activities too. This might happen in the case of the tele+ phenomenon. Most recent empirical researches have concentrated on particular applications of telecommunications and information technology, such as teleshopping (Gould et al., 1998), teleworking (Hamer et al., 1991), and teleconferencing (Mokhtarian, 1988), that all substitute travel for work, shopping, and business meetings, at varying degrees, respectively.

Salomon (1985) investigated substitution phenomenon for three different activity groups that are work, shopping and personal business, and recreation and social activities. Teleworking, which was generally thought to be a substitute for work activity, would not be realized immediately after technology is made available because of the "complex issues at play" (Salomon, 1985, 223). These issues are mostly related to the conventional work environment which is mostly associated with close supervision and complementary relationships among workers that minimize transaction costs. A second type of remote work, "neighborhood work center" comprise more realistic choice since "social, psychological and legal problems that are associated with working at home" (Salomon, 1985, 224) are solved to a large extent. For the shopping activities, Salomon (1985) argued that shopping is amenable to substitution by ICT use to the extent that individuals are occupied by other activities and are indifferent to making shopping "by touching the apple". Although shopping activity substitution would create demand for distribution systems, it will be satisfied more efficiently than the total travel demand for shopping activity itself (Salomon, 1985, 224). When transfer of information and money is required however, most of the operations can be carried out by using telecommunications.

On the other hand, ICT use cannot substitute activities that require certain specialties, thus bear a coupling constraint at a specific location such as visits to dentist or hairdresser. In this respect, recreation and social travel constitute the least amenable activities to substitution by ICT use, as these activities require coupling with other individuals or amenities at certain locations; travel is a kind of necessity in most of the instances. In fact, Salomon (1985) argued that these kinds of activities are to increase by increasing use of ICT because individuals become more aware of their environment and informed about others. Lastly, Salomon, referring to trip chains, makes a distinction between the major purpose and accompanying secondary purposes that might constitute a trip chain. Elimination of the major purpose would render the need to chain the trips obsolete; this might cause a change in space and time behavior. The result might represent a blend of complementation and modification effects.

Complementation of activities by ICT use occurs when activities increase in number or duration. The results of these two actions may be quite 
different. When activities increase in number, this normally might mean extra trips taken but when complementation occur only in activity duration this might cancel out trips too. In general, as ICT use makes individuals more informed about their as well as others' activities in many respects. Considering this, one may easily contemplate on complementation phenomenon. We can refer to Niles (1994) in this regard; some of the proper examples may be cited as follows (instead of telecommunications we prefer to use ICT):

1. ICT use makes people aware of additional general audience events and opportunities that are reached through travel, such as political rallies, professional conferences, entertainment events and shopping opportunities.

2. ICT use permits geographic decentralization of residential settlement and of organizational activity locations. Decentralization leads to higher travel consumption, because trip origins and destinations tend to be farther apart.

3. New ICT functionality resulting from digital switching and fiber optics supports the urbanization of rural communities together with associated growth in economic activity. This pattern typically causes more local automobile traffic and a flow of visitors using transportation from distant locations.

4. ICT use makes travel time more productive and more feasible for travelers; use of wireless mobile phones while traveling is the leading example (Niles, 1994).

If activities are modified in certain aspects such as timing and location without changing activity duration, then ICT use works as modification on the activity, if timing of any trip or route of any trip changes as a result of ICT exchange, its use works as modification on trip making behavior on the other hand. The behaviors in space and time are mostly regulated, harmonized and synchronized by personal, household or group logistics, which employs ICT use in most of the instances. The timing of any event, even when fixed beforehand is subject to changes or iterative adjustments. Activities are affected with respect to their fixation in space and time. The blocked activities, (or activities with strict authority constraints) are less amenable to changes by ICT use. When we consider trips (or single trips), modification can be observed in two ways: the first one is the direct consequence of the modification on activities, and the second one is the result of modification on trips themselves. The latter arises on the occasions, when the use of telecommunications causes one to change any route, mode or timing of any trip without much affecting the activities to be pursued.

\section{THE FIXED TELEPHONE VS. THE MOBILE PHONES}

The most widely available ICT mode, the conventional telephone differs from face-to-face contact in two ways: the telephone can transcend distance, but a visual channel is absent with the telephone. The nonexistence of visual channel during any communication makes the ad hoc activity different from the activity that would be pursued via face-to-face contact. An earlier empirical study on telephone calls supplies a detailed classification of telephone calls (Claisse and Rowe, 1993). According to the results of a survey reported in the study, telephone calls are made for eleven call aims which result in 16 call actions (Table 1). Further 
Table 1. Call aims and call actions (Claisse and Rowe, 1993, 279). generalization by Claisse and Rowe (1993) produced three generic call aims (private life: call aims 3, 4, 9 and 10; social life: call aims 2, 6, 7 and 8; and work life: call aims 1 and 5) and three generic actions (management: call actions 4, 5, 6, 7, 8, 9 and 13; information exchange: Actions 10, 11, 12, 3 and 2; and discussion: call actions 14 and 15).

\begin{tabular}{|l|l|}
\hline Call Aim & Call Action \\
\hline 1. Professional Activities & 1. Emergency Call \\
2. Groups, union or political & 2. Place or respond to an advertisement \\
activity & 3. Ask for a help or give help \\
3. Health problem & 4. Make an appointment, announce a visit \\
4. Buying, selling, renting & 5. Confirm an appointment, a visit \\
5. Studies, scholarship & 6. Modify an appointment, a visit \\
6. Marriage, Birth, Death & 7. Make a reservation, a visit \\
7. Invitation, Visit & 9. Make a reservation, order \\
8. Leisure, entertainment, going & 10. Discuss a problem \\
9. Put & 11. Solve a problem \\
10. Family intendance, daily & 12. Inform, get information \\
11. Other & 13. Give notice of a change of schedule \\
& 14. Spent sometime with some one \\
\hline
\end{tabular}

A further classification by Claisse and Rowe (1993) separated telephone calls into functional calls that are made to attain an objective and relational calls that are made to keep in touch with relatives or friends. However they noted that there are calls that are both functional and relational in nature, which are named as mixed calls. With the help of these detailed classifications, Claisse and Rowe (1993) reach some conclusions based on data analysis regarding telephone use:

1. Compensating use: telephone is used as a compensator for isolation from other people. Single households are keener to use telephone as a compensator,

2. Using as a tool: telephone is used to save time and manage the time constraints; The male workers generally uses telephone as a tool in this context,

3. Mixed use: telephone is used for both relational and functional calls such as conversations between youngsters,

4. Nonworking women's use: telephone is used to maintain contacts with parents and children,

5. Working women's use: telephone is used to maintain household tasks and professional tasks (Claisse and Rowe,1993).

With this introductory information regarding telephone use, in this section, information about the two different end user devices, i.e., wired (fixed) and wireless telephones (such as GSM, PHS etc.) will be introduced in order to better depict the proper implications of various devices. The fixed telephone is the conventional telephone used at homes, offices and other convenient locations. The fixed telephone needs wired connection and a specific location to connect to the system because the fixed telephone is associated with a local loop, which connects the telephone to the local exchange office, thus makes it known to the network. At another location, 
the network cannot recognize it. The home and the office telephones are the most basic two fixed telephones. Hägerstrandian constraints apply to the fixed telephones at varying degrees. In order to make a connection, hence communication successful, the parties of the communication has to be at the proper locations at the same time. Thus fixed telephone bears coupling constraint for the parties of the communication process. Similarly, certain telephones are actively used or accessed within the hours designated. The reach to an office by telephoning is subject to the working hours, thus bearing authority constraint and possibly other authority constraints apply when the calling party is first welcomed by another person or a machine, as a buffer to filter the access to the called party. For example, one of the job definitions of the secretaries in the offices is to filter the incoming calls. Apart from these, there are also established rules of telephoning. For example, it is not common to telephone someone during the times when everybody generally has retired the day.

On the other hand, the most common wireless telephone is the mobile phone (although there are significant technological differences, we also consider the PHS devices in this set too). The mobile phone has spread throughout the world at an incredible pace during the past two decades. Spector (1993) notes, "when the history of communications in the 20th century is written, 1990s will be remembered as the decade of wireless communications" (Spector, 1993, 403). The most striking property of the mobile phones is their combined portability and intelligence. Jauréguiberry (2000) notes, "by destroying communicational unity in space and time, one no longer needs to be in a specific place to make a telephone call. The mobile telephone makes it possible for one not to be at loss when confronted with last-minute hitches" (Jauréguiberry, 2000, 256). The most of the added services (some of which also applies to fixed telephone) are common to the mobile phones, e.g., Caller ID, call duration, call history as well as telephone diary. Short message services are also vary popular in mobile phones too. The coupling constraint, which applies to fixed telephone, is obsolete in the case of the mobile phones as they are carried by the individuals, hence individuals can be accessed any time within the boundaries of the authority constraints.

As a personalized item, mobile phone is an active element of trip making behaviors of individuals. Nobis and Lenz (2009), using panel data collected in Germany for 2004 and 2007 found interesting results regarding individual mobility with mobile phone use. A general decline in mobility index, an index summarizing information contained in ordinal scaling of frequency of different travel modes, is countered by the mobile phone use: users who reported increase in mobility index. However, the results seem a little counter intuitive when trip making globally is increasing. Şenbil and Kitamura (2003) instead found significant increase in activity participation by ICT use, i.e., a definite complementation effect. Using structural equations, Senbil and Kitamura (2003) assessed the trip making behavior of individuals along with their telecommunications habits in a travel demand context, the results they obtained that frequent use of telecommunications foster trip making behaviors. Although this study relied on data collected in Japan, similar results are found using US data by Mokhtarian and, Meenakshisundaram (1999), Choo et al. (2007), Choo and Mokhtarian (2007) too. 


\section{ICT NETWORK EXTERNALITIES AND SOCIAL NETWORK}

When a new user adopts ICT with $\mathrm{N}$ users, $(\mathrm{N}+1)$ th user adds $2 \mathrm{~N}$ potential links to the communications network. This positive network externality is related to the increased potential links in the network (there are negative network externalities too. However, compared to the positive network externalities they remain negligible); hence it can be viewed as a benefit not only to the new user but also to the existing users as well. In other words, ICT network externality demonstrates the fact that the number of users already in the system affects the utility derived from ICT use ceteris paribus. For example, telecommunications network externality is one of the most striking realities of the diffusion of the telephone service among the population. A huge network that indicates the existence of many users means that one can access almost anybody by telecommunications within the confines of the space-time constraints. So the accessibility supplied by a bigger network when compared to a smaller one is higher at first sight indicates the potential for extensive interactions among the users.

In fact, the intensity of interactions in a telecommunications network is often subject to the confines of the social groups (individuals affiliated with each other by kinship, acquaintance, organization etc. e.g., family, friends, colleagues). Intra-group communications is always more intense then intergroup communications. Therefore the intensity of telecommunications network usage is generally associated with the intensity of intra-group communications which can be visualized by using social networks.

Social network is a social structure that includes individual members with different interdependencies. According to Marsden (2000), social networks which are omnipresent in the modern society serve as an important information exchange media, emotional support in times of crisis, as well as instrumental aid such as help with household tasks among others. The social dimension embedded in the social networks often is important facilitator for travel demand, however traditional approach used in the travel demand analysis usually takes an individualistic approach. More specifically, the traditional approach ignores the number of people involved in activities and their relations to each other (Carrasso et al., 2008). In fact, the social networks can be considered in many different contexts with respect to the activities, hence the travel demand. For example, Webster et al. (2001) visualizes the differences between two social networks in two different contexts that are university campus and work place, and find that the relationships are very different between individuals with and without institutional constraints. In other words, in the university people who meet frequently tend to eat together in most of the instances, but in a workplace people do not exhibit such behavior.

Considering the interactions between individuals via ICT, the most indicative part of the ICT network for communication interactions is the one overlapping with the social network: the intensity of interactions in any telecommunications network is closely related to the social networks. But this does not necessarily mean that the intensity of interactions would be translated into effects on activities of the individuals. For example, in a social network embracing work relationships, the frequency of ICT communications and face-to-face meetings might be negatively correlated while in another social network among close friends, ICT use might easily catalyze communications for face-to-face meetings in the form of joint activities. 


\section{DISCUSSION}

ICT relax space-time constraints at varying degrees. By instant communications in most of the instances, one can transcend coupling, capability as well as authority constraints. You can shop at midnight in USA without the need to travel, chat with a friend without coming together a café, or download electronic journal papers without going to the Library. Variation in space and time relaxation is has important implications for individual activities, hence the travel demand. In the short term basis, weekly individual activities are affected variably by the three characteristics of ICT: i.) Simultaneity, ii.) Time Lag, and iii.) Availability. It should be expected that the ICT effects will overcome spatial and temporal constraints imposed on the individuals to the extent that the devices and applications improve in simultaneity (interactive communications) and the time lag is decreased between communication episodes.

The most important and well-celebrated ICT benefit is the relaxation gained in traversing space at the speeds that the telecommunications networks allow. This benefit has been improved significantly in the recent years as both data and visual communications offered by the high-speed telecommunications network have become ordinary supplements of the certain facets of daily life, namely, working life, private life etc. The results of the relaxations on the coupling constraints are twofold: time saved in many respects (such as time released from trips to coupling) will be used for other activities or similar activities but at different locations.

On the other hand, it should be expected that relaxation of coupling constraint should have repercussions on activity engagement. At the global level, outsourcing of many of the tasks has become available which is indicative of the changes in the composition of the future work force at the global level (Graham and Marvin, 1996; Castells, 1989; Harvey, 1989). At the individual level, this might increase further activity engagement (although telephone, or popularly known internet chats might induce face-to-face interactions with sight, smell and touch senses, most of which cannot be supplied by the available technologies and would not be substituted in most of the instances psychologically).

It has to be stressed that the telecommunications contacts are very different in nature. Examples given by Claisse and Rowe (1993) display a significant effort in this regard. Functional and relational calls should have different implications on the individual activity engagement. A mother tracking her children by telecommunications and a woman reserving a hotel room for weekend excursion have very different objectives met by telecommunications convergence. The repercussions of these different communications on other activities (the former is relational and the latter is functional) are very different in fact. In the former case, the caring mother can use space and time for other activities (meet friends, do shopping freely etc.); in the latter case, only one objective is attained and the flow of activities in time are not affected.

Authority constraints seem to be relaxed with respect to continuous existence in time and effective (and in times efficient) coordination in space. Especially, devices and applications that can store information conveyed at the other side of the communications offer significant improvements in the case of authority constraints. The tele-secretary services installed in both the conventional and mobile phones, telephone diaries and palmlike mobile phones relax many of the authority constraints in this regard. Similarly, e-commerce is also a significant achievement on the typical 
authority constraint imposed on individuals who are occupied during the available times of the activity in consideration.

It has been found that voice communications over ICT are shorter than the face-to-face communications (e.g., Reid, 1977). In addition to savings obtained from obsolete trips for face-to-face contacts, time is utilized more effectively and not only savings in trip time but also activity duration should be expected to shorten in this regard. Many of the working hours (especially in the service sector) have been being organized again nowadays. Europe in general, Netherlands in particular leads the world in this regard (see for example Emmerink and van Beek, 1995). Besides, work activity itself is transforming in many respects too. ICT frees some of the professions from their locational constraints by providing access to fast communications almost everywhere. Ordinary functioning of the daily life changes in time episodes with many technological improvements along with the societal changes. Daily schedules are maintained in electronic diaries that have access to both telecommunications and the World Wide Web which enable individuals adjust themselves to impulsive diversions from daily schedules. The result is more interactive society. Besides, as information society has been flourishing and bourgeoning in many respects; at the same time, leisure society is also emerging in the developed world (see Gershuny, 1992). Time available to invest in leisure activities has increased significantly since the beginning of the 20th century. This has developed in close association with the improvements in the transportation system. Development in ICT has just carried this process to the next level.

As the societal and technological transformation takes its pace, the societal functioning also improves in many respects. Activity logistics (scheduling, coupling, path finding etc.) is one of the areas in which significant improvements is expected to be seen in the near future (we are experiencing some of these technological improvements nowadays too) as it converges with the personal logistics that involve ICT utilization, utilization of transportation modes, etc. The increase of ICT in the society as well as its intensive/ extensive use offer many prospects for both businesses and individuals. Network externality is the core concept in this regard. Prompt information retrieval and update make activity planning excel in many respects, e.g., exact coupling in space and time, route planning, flash information on authority constraints etc. In this regard, use of mobile phones offers increased flexibility in space-time over the conventional telephone. The use of mobile phones allows instantaneous updating of activity plans with respect to impulsive information retrievals.

\section{REFERENCES}

CASTELLS, M. (1989) Informational City, Basil Blackwell, Oxford, U.K.

CARRASCO, J. A., HOGAN, B., WELLMAN, B., MILLER, E.J. (2008) Agency in Social Activity Interactions: The Role of Social Networks In Time And Space, Tijdschrift voor Economische en Sociale Geografie (99) 562-83.

CHOO, S., LEE, T., MOKHTARIAN, P. L. (2007) Do Transportation and Communications Tend to Be Substitutes, Complements, or Neither?: U.S. Consumer Expenditures Perspective, 1984-2002, Transportation Research Record (2010) 121-32. 
CHOO, S., MOKHTARIAN, P. L. (2007) Telecommunications and Travel Demand and Supply: Aggregate Structural Equation Models for The US, Transportation Research A (41) 4-18.

CLAISSE, G., ROWE, F. (1993) Domestic Telephone Habits and Daily Mobility, Transportation Research A (27) 277-90.

DE SOLA POOL, I., ed. (1977) The Social Impact of The Telephone, The MIT Press, Boston.

DE SOLA POOL, I. (1982) Communications Technology and Land Use, Internal Structure of The City, ed. L.S. Bourne, Oxford University, Oxford; 450-8.

DE SOLA POOL, I. (1983) Forecasting the Telephone: A Retrospective Technology Assessment, ABLEX Publications, Norwood, New Jersey.

EMMERINK, R.H.M., VAN BEEK, P. (1995) Empirical analysis of the work schedule flexibility,: The Tinbergen Institute, The Netherlands.

GERSHUNY, J. (1992) Are We Running Out of Time? Futures (24) 3-22.

GOULD, J., GOLOB, T., BARWISE, P. (1998) Why Do People Drive To Shop? Future Travel and Telecommunications Trade-offs, Presented at the 77th Annual Meeting The Transportation Research Board Annual Meeting, National Research Council, Washington, DC, January.

GRAHAM, S., MARVIN, S. (1996) Telecommunications and The City, Routledge, London.

HAMER, R., KROES, E., VAN OOSTSTROOM, H. (1991) Teleworking in Netherlands: An Evaluation of Changes in Travel Behavior. Transportation (18) 365-82.

HARVEY, D. (1989) The Condition of Postmodernity: An Enquiry into The Origins of Cultural Change, Blackwell, Oxford, England.

HÄGERSTRAND, T. (1970) What About People in Regional Science? Papers of the Regional Science Association (24) 7-21.

JAURÉGUIBERRY, F. (2000) Mobile Telecommunications and The Management of Time, Social science Information (39) 255-68.

JOH, C-H., ARENTZE, T. A., TIMMERMANS, H. J. P. (2001) Understanding Activity Scheduling And Rescheduling Behaviour: Theory And Numerical Illustration. GeoJournal (53) 359-71.

KATZ, J. E., (2001) Telephone, International Encyclopedia of the Social and Behavioral Sciences, eds. N.J. Smelser, P.B. Baltes, Pergamon Press, Oxford; 15558-65.

KATZ, J. E., ASPDEN, P. (1998) Theories, Data, and Potential Impacts of Mobile Communications, A Longitudinal Analysis of U.S. National Surveys, Technological Forecasting and Social Change, (57) 133-56.

LEE, M. S., McNALLY, M. G. (2003) On The Structure of Weekly Activity/ Travel Patterns, Transportation Research A (37) 823-39.

MARSDEN, P. V. (2000) Social Networks, Encyclopedia of Sociology, eds. E. F. Borgotta, R. J.V. Montgomery, MacMillan Reference USA, N.Y.; 2727-35. 
MOKHTARIAN, P. L. (1988) An Empirical Evaluation of The Travel Impacts of Teleconferencing, Transportation Research A (22) 283-9.

MOKHTARIAN, P. L. (1990) A Typology of Relationships Between Telecommunications and Transportation, Transportation Research $A$ (24) 231-42.

MOKHTARIAN, P., L., MEENAKSHISUNDARAM, R. (1999) Beyond TeleSubstitution: Disaggregate Longitudinal Structural Equations of Communications Effects, Transportation Research C (7) 33-52.

NILES, J.S. (1994) Beyond Telecommuting. Available at: http:/ / www.lbl. gov/ICSD/Niles / (Accessed May 1, 2009)

REID, A.A.L. (1977) Comparing Telephone with Face-to-face Contacts, The Social Impact of The Telephone ed. I. de Sola Pool, The MIT Press, Boston; 386-414.

SALOMON, I. (1985) Telecommunications and Travel-Substitution or Modified Mobility? Journal of Transport Economics and Policy (19) 21935.

SALOMON, I. (1986) Telecommunications and Travel Relationships: A Review, Transportation Research A (20) 223-38.

ŞENBİL, M., KITAMURA, R. (2003) Simultaneous relationships between telecommunications and activities, 10th International Conference on Travel Behavior Research, August 10-15, 2003, Lucerne.

SOJA, E. (1989) Postmodern Geographies, Verso, London.

SPECTOR, P. (1993) Wireless Communications and Personal Freedom, Telecommunications Policy (17) 403-7.

WEBSTER, C. M., FREEMAN, L. F., AUFDEMBERG, C. G. (2001) The Impact of Social Context on Interaction Patterns. Journal of Social Structure (2), http: / / www.cmu.edu / joss / content/ articles / volume2/Webster.html, (Accessed May 1, 2009).

Alındı: 12.06.2009; Son Metin: 03.09.2009

Anahtar Sözcükler: bilgi ve iletişim teknolojileri; telefon; aktivite tabanlı ulaşım talebi; bireysel ulaşım; sosyal ağ.

\section{BİLGİ VE İLETIŞİM TEKNOLOJILERİNİ DEĞİŞİM ÇAĞINDA ANLAMAK: BİREYSEL ULAŞIMDAKİ BEKLENTİLER NELERDİR?}

Bugünlerde bilgi ve iletişim teknolojilerinde (BİT) görülen hızlı gelişme, pazarın da hızlı gelişmesini sağlamaktadır. BİT, mekan ve zaman kısıtlarını gevşeterek karşılıklı bilgi değişimini de desteklemektedir. Aktivite tabanlı ulaşım talebinde BİT bireysel aktivite-yolculuklarını değişik ölçülerde ikame edebilir, tamamlayabilir, ya da değiştirebilir. Diğer yandan, BİT ağ sosyal ağı da pozitif olarak etkilemektedir. Sonuç olarak, BİT kullanımı aktivite-yolculuk talebini aktivitelere katılımı arttırarak tamamlamaktadır. Ayrıca, konvansiyonel telefon gibi BİT modern toplum ve yaşamın değişimine bir sürü yönden destek vermektedir. 